\title{
Método de oficinas no processo de Educação Permanente em Saúde à luz de Charles Maguerez
}

\author{
Workshop method in the process of Permanent Health Education in the light of Charles Maguerez
}

\author{
Amanda Akemi Ribeiro Nakaa, Maria Adelane Monteiro da Silvab, Renata Soares Moraisa, \\ Camila Martins de Oliveirac, Andrea Carvalho Araújo Moreirab ${ }^{b}$, Viviane Oliveira Mendes Cavalcanted \\ a Enfermeira residente em neonatologia da Santa Casa de Misericórdia de Sobral, Ceará, Brasil.

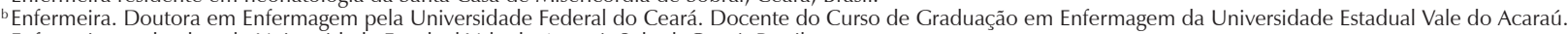 \\ 'Enfermeira graduada pela Universidade Estadual Vale do Acaraú, Sobral, Ceará, Brasil. \\ ${ }^{d}$ Enfermeira. Mestre em Saúde da Família pela Universidade Federal do Ceará. \\ Fontes de Financiamento: Programa Institucional de Bolsas de Iniciação em Desenvolvimento Tecnológico e Inovação (PIBITI)
}

RESUMO

Objetivo: Analisar o método de oficinas desenvolvido com base na teoria de Charles Maguerez utilizado no processo de Educação Permanente em Saúde. Além disso, conhecer a percepção dos profissionais de saúde sobre os efeitos da utilização desse método.

Materiais e Métodos: Estudo exploratório e descritivo com abordagem qualitativa, desenvolvido em um Centro de Saúde da Família (CSF) de um município do Norte do Ceará. Teve como sujeitos os profissionais da equipe de saúde do CSF de um município do Norte do Ceará.

Resultados: Foram entrevistados 15 profissionais que participavam das atividades de Educação Permanente em Saúde na unidade. A análise dos dados se deu com base nos pressupostos do método do Arco de Charles Maguerez, onde foram originadas as seguintes categorias: O método utilizado no processo de Educação Permanente em Saúde; Refletindo/discutindo sobre a realidade; Apontando resolução para os problemas e transformando as práticas cotidianas; Desafios para o uso do método nos momentos de Educação Permanente em Saúde na Estratégia Saúde da Família. Há uma valorização do método por estimular a participação da equipe e é visto como estimulador de reflexões tanto em relação à assistência prestada enquanto equipe para a comunidade quanto ao seu próprio fazer enquanto profissional. Surgiram propostas relacionadas à periodicidade das oficinas e a busca de conhecer mais o Arco de Charles Maguerez.

Conclusão: O uso da teoria do Arco de Charles Maguerez na Educação Permanente em Saúde provocou envolvimento com a realidade vivenciada, com as potencialidades do território e da própria equipe.

Palavras-chave: educação permanente; gestão em saúde; atenção básica à saúde.

\section{ABSTRACT}

Objective: To analyze the workshop method developed based on the theory of Charles Maguerez used in the process of Permanent Education in Health. In addition, to know the perception of health professionals about the effects of the use of this method.

Materials and Methods: Exploratory and descriptive study with a qualitative approach, developed in a Family Health Center (CSF) of a municipality in the north of Ceará. It had as subjects the professionals of the health team of the CSF of a municipality of the North of Ceará.

Results: Fifteen professionals who participated in the activities of Permanent Health Education in the unit were interviewed. The analysis of the data was based on the assumptions of the Charles Maguerez Arch method, where the following categories were originated: The method used in the process of Permanent Education in Health; Reflecting/discussing about reality; Pointing resolution to problems and transforming everyday practices; Challenges for the use of the method in the moments of Permanent Education in Health in the Family Health Strategy. There is a valuation of the method by stimulating the participation of the team and it is seen as a stimulator of reflections, both in relation to the assistance given as a team to the community and to their own doing as a professional. There were proposals related to the periodicity of the workshops and the search to know more about the Arch of Charles Maguerez. Conclusion: The use of the Charles Maguerez Arch theory in the Permanent Education in Health provoked involvement with the actual reality, the potentialities of the territory and the team itself.

Keywords: continuing education; health management; primary health care.

\section{Correspondência:}

AMANDA AKEMI RIBEIRO NAKA

Travessa Vereador Salvimar, 316 - Centro

62140-000 Massapê, CE, Brasil

E-mail: amanda.kemi@hotmail.com 


\section{INTRODUÇÃO}

A Educação Permanente em Saúde (EPS) é considerada uma aprendizagem no trabalho, na qual o aprender e o ensinar se incorporam ao cotidiano das organizações. Baseia-se na aprendizagem significativa e na possibilidade de transformar as práticas profissionais, sendo formulada a partir dos problemas enfrentados na realidade e levando em consideração os conhecimentos e as experiências que as pessoas já têm 1 .

A Educação Permanente em Saúde está centrada no exercício cotidiano do processo de trabalho, na valorização do trabalho como fonte de conhecimento, na articulação entre atenção à saúde, gestão e controle social, voltada à multiprofissionalidade e à interdisciplinaridade, com estratégias de ensino contextualizadas e participativas ${ }^{2}$.

Compreende-se que os profissionais de saúde que participam do processo de educação permanente vivenciam os problemas e as necessidades cotidianas dos serviços de saúde. O método do Arco de Charles Maguerez é utilizado para trabalhar com oficinas, sendo considerado uma alternativa transformadora e dialógica que parte de uma parcela da realidade e retorna para ela, visando transformá-la em algum grau. Essa metodologia prevê uma ação na realidade, a partir de uma compreensão, com base em saberes adquiridos pela investigação e reflexão, fundamentados teoricamente, implicando uma consciência social ${ }^{3}$.

A Metodologia da Problematização caracteriza-se pela aplicação do Esquema do Arco, proposto por Charles Maguerez e divulgado por Bordenave e Pereira ${ }^{4}$ e tem como ponto de partida a realidade vivida, aquela parcela da realidade em que o tema que está sendo ou será trabalhado está acontecendo na vida real. Tal percurso propõe uma ação transformadora da realidade, em algum grau, conforme explica Berbel ${ }^{3}$.

O estudo justifica-se pelo interesse em conhecer a visão dos profissionais sobre o uso do método do Arco de Charles Maguerez no processo de Educação Permanente em Saúde do qual participam.

A relevância desse estudo se dá por meio da colaboração a partir da reflexão e análise sobre a utilização do Arco de Charles Maguerez nas oficinas para o processo de Educação Permanente em Saúde no qual os profissionais estão inseridos. Também pela possibilidade de envolvimento com as vivências, de repensar estratégias e dispor de novos métodos que embasem esses momentos.

O estudo objetiva analisar o método de oficinas desenvolvido com base na teoria de Charles Maguerez utilizado no processo de Educação Permanente em Saúde.
Assim como conhecer a percepção dos profissionais de saúde sobre os efeitos da utilização desse método.

\section{MATERIAIS E MÉTODOS}

Estudo exploratório e descritivo com abordagem qualitativa. A abordagem qualitativa, na perspectiva de Minayo, é a que melhor se conforma na investigação de grupos e segmentos delimitados e focalizados, de histórias sociais sob a ótica dos atores, de relações e para análises de discursos e de documentos, pois permite desvelar processos sociais ainda pouco conhecidos referentes a grupos particulares, propicia a construção de novas abordagens, revisão e criação de novos conceitos e categorias durante a investigação ${ }^{5}$.

A pesquisa foi desenvolvida no ano de 2015. O cenário foi um Centro de Saúde da Família (CSF) do município de Sobral, localizado na zona norte do estado do Ceará. Os sujeitos do estudo foram profissionais da equipe de saúde deste CSF que participam do processo de Educação Permanente em Saúde. Estes foram convidados a colaborar com a pesquisa, momento no qual foram apresentados os objetivos do estudo e, para aqueles que aceitaram contribuir, o Termo de Consentimento Livre e Esclarecido.

O CSF conta com: dois médicos; cinco enfermeiras; cinco técnicas de enfermagem; dezesseis Agentes Comunitários de Saúde (ACS); três dentistas; dois auxiliares de saúde bucal; cinco profissionais do Núcleo de Apoio à Saúde da Família (NASF), sendo um nutricionista, um fisioterapeuta, um farmacêutico, um psicólogo e um assistente social; cinco profissionais da Residência Multiprofissional em Saúde da Família distribuídos nas categorias: educador físico, fonoaudióloga, assistente social, terapeuta ocupacional e fisioterapeuta; 5 auxiliares administrativos; dois seguranças; e quatro vigilantes.

A coleta de dados se deu por meio de entrevista semiestruturada que buscou conhecer a percepção dos profissionais de saúde sobre o método utilizado no processo de Educação Permanente em Saúde. Utilizando como ponto de partida as seguintes questões disparadoras:

1. O que você sabe sobre a forma como as atividades de Educação Permanente em Saúde estão sendo realizadas nas rodas de equipe desta unidade?

2. Como você avalia a utilização da teoria do Arco de Charles Maguerez no processo de Educação Permanente em Saúde?

3. Houve mudanças na sua conduta como profissional a partir da utilização da teoria do Arco de Charles Maguerez?

4. Quais a contribuições da utilização deste método para o território? 
5. Quais mudanças foram adotadas na organização do serviço?

6. Quais potencialidades e limites identificados na aplicação do Arco de Charles Maguerez no processo de Educação Permanente em Saúde?

7. Que sugestões você daria para melhoria desse processo de Educação Permanente em Saúde com uso da teoria do Arco de Charles Maguerez?

As informações foram gravadas e transcritas de acordo com o consentimento dos participantes. Também foram levantadas informações de caracterização dos sujeitos e buscou-se analisar o impacto do método de oficinas baseado no Arco de Charles Maguerez nas condutas, as principais dificuldades enfrentadas por esses profissionais e sugestões para aperfeiçoar o processo a partir da implementação do método.

A teoria do Arco de Maguerez é dividida em cinco etapas. A primeira etapa é a observação da realidade. Na segunda etapa, busca-se identificar os pontos-chave do problema, na terceira etapa, reconhecida como metodologia da problematização, pratica-se a teorização. Na quarta etapa, a proposição de hipóteses e soluções e na quinta e última etapa, a aplicação à realidade ${ }^{6}$.

A análise dos dados deu-se com base nos pressupostos do método do Arco de Maguerez. O conteúdo das entrevistas foi lido, codificado, analisado e organizado em categorias discutidas com base na literatura pertinente ao tema. Essa técnica consistiu basicamente em analisar o material verbal coletado em pesquisas que têm depoimentos como sua matéria prima, extraindo de cada um destes depoimentos as Ideias Centrais ou Ancoragens e as suas correspondentes Expressões Chave $^{7}$.

Este estudo faz parte de uma pesquisa intitulada "A Educação Permanente em Saúde para atenção qualificada às gestantes adolescentes na Estratégia Saúde da Família". O projeto foi submetido ao Comitê de Ética em Pesquisa da Universidade Estadual Vale do Acaraú e aprovado sob CAAE № 11098312.9.0000.5053, obtendo parecer favorável № 213.002. O estudo obedeceu aos princípios estabelecidos pela Resolução 466 de 12 de Dezembro de 2012, do Conselho Nacional de Saúde, que trata de pesquisa envolvendo seres humanos. Durante a condução do estudo foram respeitados os princípios básicos da bioética: autonomia, beneficência, não maleficência, justiça e equidade ${ }^{8}$.

\section{RESULTADOS E DISCUSSÃO}

A construção da Política Municipal de Educação Permanente em Saúde em Sobral, Ceará, iniciou-se em 1997, concomitante com o processo de organização do Sistema de Saúde responsável pela formação e capacitação de pessoal para a gestão do Sistema Único de Saúde9.
Na Estratégia Saúde da Família (ESF) de Sobral, Ceará, a EPS é apoiada pelo tutor, que atua em uma abordagem educativa para potencializar a capacidade do coletivo e mediar a aprendizagem ativa dos sujeitos dos territórios, buscando construir espaços de reflexão das práticas dos profissionais de saúde, considerando a autonomia destes, a partir da compreensão e problematização de seu próprio processo de trabalho, visando a transformação dessas práticas de forma significativa. Estes momentos ocorrem no contexto de atuação dos profissionais, onde estes identificam suas necessidades de aprimoramento, dialogam entre si, permeados por uma relação de troca de saberes e responsabilização, ocorrendo a construção de novos conhecimentos.

\section{O método do Arco na Educação Permanente em Saúde}

A primeira etapa da teoria do Arco de Maguerez consiste na observação do que ocorre na realidade próxima, relacionada com a temática a ser investigada. Consideramse, além das experiências anteriores e atuais do próprio pesquisador, a percepção de outras pessoas que podem ser consultadas. A observação pode se dar de diversas formas, assim como o registro inicial do que está ocorrendo e do contexto em geral ${ }^{3}$.

Na segunda etapa, os sujeitos realizam uma eleição do que foi observado na realidade. Analisa-se o que é realmente importante, identificam-se os pontos-chave do problema ou assunto em questão e as variáveis determinantes da situação. É o momento de síntese após a etapa da escolha do que será estudado sobre o problema, os aspectos que precisam ser conhecidos e melhor compreendidos, para buscar uma resposta ${ }^{10,11}$.

Na terceira etapa a problematização se dá por meio da teorização através do que já foi visto na observação da realidade e nos pontos-chave, no sentido de adequar e potencializar as atividades dos profissionais de saúde, que se configurarão como passos para a resolução do problema ${ }^{3}$.

Nesta etapa os participantes devem ser orientados a buscar as evidências científicas e uma explanação teórica do problema, mobilizando a capacidade dos pesquisadores para reunir um acervo teórico-conceitual que possa apoiar as atividades educativas propostas e os problemas a serem resolvidos ${ }^{12}$.

Na fase de Hipótese de solução ou planejamento definese o contexto em que o processo vai ser desenvolvido, quais objetivos serão alcançados, que estratégias serão utilizadas na aplicabilidade do processo, a viabilidade destas num determinado grupo, análise do nível de governabilidade do problema pelo processo de educação permanente, coerência com os processos da gestão da realidade a ser trabalhada ${ }^{12}$. 
Esta última etapa se dá pela discussão das hipóteses elaboradas para a confirmação destas ou refutação, de modo a atingir mais diretamente o problema, a fim de resolvê-lo ou de desencadear passos na direção de sua solução. Portanto, este momento vai além de um mero exercício intelectual, pois a prática que corresponde a essa etapa implica num compromisso do pesquisador com o seu meio e o compromisso social e político é mais uma vez acionado. Assim, do meio observamos os problemas e para o meio devolvemos uma resposta, visando transformá-lo em algum grau 6 .

\section{Percepção dos profissionais acerca do método de oficinas com base no Arco de Maguerez}

A partir da aplicação da entrevista semiestruturada, foram entrevistados 15 profissionais que participavam das atividades de Educação Permanente em Saúde na unidade, sendo 5 enfermeiras, das quais 1 exercia cargo de gerente da unidade, 3 técnicos de Enfermagem, 5 Agentes Comunitários de Saúde, 1 Nutricionista do Núcleo de Apoio a Saúde da Família e 1 Fonoaudióloga da Residência Multiprofissional em Saúde da Família. Dentre as impossibilidades de incluir os 54 profissionais do CSF, pode-se citar a não aceitação em participar do estudo e indisponibilidade de alguns por encontrarem-se no período de férias ou licença.

A faixa etária prevalente dos sujeitos do estudo foi de 35 a 40 anos, sendo a menor idade 24 e a maior, 45 . Os profissionais que possuíam graduação tinham de 1 a 15 anos de formação, com cursos de especialização em Saúde da Família, Urgência e Emergência, Gestão em Saúde Pública e Vigilância Sanitária dos Alimentos. Sobre o tempo de atuação na Estratégia Saúde da Família e tempo de atuação no município de Sobral, o período mínimo foi de 6 meses e o máximo de 18 anos.

As informações obtidas acerca da percepção dos profissionais foram organizadas em 4 categorias: $\mathrm{O}$ método utilizado no processo de Educação Permanente em Saúde; Refletindo/discutindo sobre a realidade; Apontando resolução para os problemas e transformando as práticas cotidianas; Desafios para o uso do método nos momentos de Educação Permanente em Saúde na Estratégia Saúde da Família.

\section{O método utilizado no processo de Educação Permanente em Saúde}

O fato de o Arco possuir fases a serem seguidas é, na concepção dos profissionais, uma maneira de tornar a EPS mais organizada e regular. Diminuindo assim as dificuldades para os participantes e até mesmo para os facilitadores responsáveis por conduzir esses momentos.
"É muito bom para o planejamento da oficina e para quem vai facilitar porque tem um passo a passo." (Nutricionista)

"Ajudou a manter sistemático o processo de Educação Permanente que era eventualmente." (Gerente)

De acordo com o Ministério da Saúde, o processo de Educação Permanente em Saúde requer elaboração, desenho e execução a partir de uma análise estratégica e da cultura institucional dos serviços de saúde em que se insere. A teoria do Arco de Charles Maguerez vem auxiliando os profissionais a definir seu processo de Educação Permanente em Saúde ${ }^{1}$.

Percebe-se o estabelecimento de comparações entre a forma em que acontecem as atividades de Educação Permanente em Saúde atualmente e como acontecia anteriormente. O método foi visto positivamente e apresenta vantagens principalmente por dar uma conotação mais dinâmica ao processo. Isso reflete também na adesão da equipe no processo, pois desperta maior interesse.

"O que está acontecendo é que a forma é mais dinâmica em relação às outras que a gente tinha. Ela faz uma alusão dos temas de uma forma mais dinâmica com a participação da maioria das pessoas." (Enfermeira 4)

Todavia, o seguimento de todas as fases não está claro para todos os entrevistados e se configura como uma limitação identificada na realização das oficinas de EPS.

"É um limite a não conclusão de todo o processo do Arco." (Enfermeira 4)

$\mathrm{O}$ arco de Maguerez tem como ponto de partida e chegada a realidade social, levando os sujeitos a exercitarem a relação ação-reflexão-ação, pedra angular de orientação do processo. Nesta categoria os entrevistados expõem a vantagem da utilização do método para fins de sistematizar as atividades de Educação Permanente ${ }^{13}$.

De acordo com a Política Nacional de Educação Permanente, apesar da importância e difusão da capacitação, nem sempre se alcançam os resultados esperados, ou seja, nem sempre esses projetos se convertem em ação. Não são suficientes para reconsiderar as próprias práticas da capacitação, nem levam à análise dos múltiplos sentidos que a capacitação assume nos distintos projetos ${ }^{1}$.

"Sempre tem aquele profissional que não gosta ou que não quer participar e o método exige que todo mundo participe. [...] Talvez o fato de a metodologia ser aplicada na roda, o fato de todo mundo ter que participar, inquieta algumas pessoas." (Nutricionista) 
"Mas assim, a maior limitação que eu acho são as próprias pessoas, de interagir mais. A interação da equipe." (Enfermeira 2)

Acredita-se que a participação mais ampla dos profissionais envolvidos no processo contribui para a adequação cada vez mais efetiva do método à realidade do território, da comunidade e do próprio processo de trabalho. Existem diversas maneiras de participação, classificando-as como participação de fato, espontânea, imposta, voluntária, provocada e concedida. $\mathrm{O}$ autor também observa que a participação pode ter objetivos tanto de cunho pessoal, como sociais, políticos, organizacionais, entre outros ${ }^{11}$.

A palavra participação tem origem no latim particeps, que quer dizer participante, aquele que tem parte em, faz parte de, toma parte, aquele que partilha ou tem quinhão. Tal significado pode parecer simples, mas muitas interpretações podem surgir dos diferentes conceitos que estas expressões geram em relação à forma e à intensidade de participação dos indivíduos ${ }^{11}$.

Na opinião dos entrevistados, há uma valorização do método por estimular a participação da equipe nas oficinas baseadas na Teoria do Arco. Isso se deve tanto ao método em si quanto à motivação dos profissionais. Por outro lado, apesar do aumento relatado, alguns ainda impõem barreiras quando se trata de interagir e contribuir durante os momentos de Educação Permanente.

"Fez com que a gente conseguisse adesão maior dos profissionais porque ficou uma coisa mais dinâmica." (Nutricionista)

A fala reflete a percepção das profissionais de enfermagem acerca do método como inovador e renovador das práticas de Educação Permanente em Saúde da equipe. Considera-se uma vantagem em relação aos métodos anteriores, principalmente pela motivação causada.

Todavia, apesar da utilização do Arco proporcionar participação e os profissionais reconhecerem as oficinas como espaço que promove e incentiva o envolvimento de toda a equipe, alguns profissionais afirmam ser necessária uma maior interação. Isso se justifica pela adaptação ainda em curso das pessoas com as oficinas e com a metodologia que requer essa relação participativa entre o grupo.

\section{Refletindo/discutindo sobre a realidade}

No que se refere à seleção dos temas para trabalhar nas oficinas, os entrevistados demonstram exercer papel fundamental. Isso acontece visando priorizar as necessidades da equipe do CSF, assim como do território e buscando, principalmente, promover um melhor aprendizado.
"Como os temas foram escolhidos pela gente, então alguns que eu não dominava, acabei aprendendo." (Fonoaudióloga)

A Educação Permanente é feita a partir dos problemas enfrentados na realidade e leva em consideração os conhecimentos e as experiências que as pessoas já têm. Propõe que os processos de educação dos trabalhadores da saúde se façam a partir da problematização do processo de trabalho e considera que as necessidades de formação e desenvolvimento dos trabalhadores sejam pautadas pelas necessidades de saúde das pessoas e populações ${ }^{1}$.

\begin{abstract}
"Inicialmente, a gente começou a agrupar por tema as necessidades de conhecimento de cada profissional e se tivesse alguma necessidade urgente do território, a gente colocaria na frente. Como por exemplo: teve o surto de sarampo e a gente viu a necessidade de fazer educação permanente sobre sarampo. Teve um caso de abandono de tratamento de tuberculose. Algumas pessoas que estavam tendo resistência e nós fizemos de acordo com as necessidades do território e do conhecimento dos profissionais." (Gerente)
\end{abstract}

No discurso, a profissional reproduz o seguimento do arco nos momentos de eleger os temas das oficinas, principalmente no que diz respeito à primeira fase, que consiste na observação da realidade.

A primeira etapa do Arco de Charles Maguerez é a de observação da realidade. É o momento em que os sujeitos envolvidos podem olhar atentamente para a realidade, escolhendo aspectos que precisem ser desenvolvidos, trabalhados, revisados ou melhorados ${ }^{10,11,14}$.

O método utilizado nas atividades de EPS também é visto como estímulo de reflexões tanto em relação à assistência prestada enquanto equipe para a comunidade quanto ao seu próprio fazer enquanto profissional.

"É um método que é bom, a gente pode estar refletindo e trazendo esse retorno. Traz uma reflexão maior para que seja prestada uma assistência melhor. A gente acaba refletindo mais um pouco e além do que está." (Enfermeira 3)

Essas atitudes reflexivas são muito importantes para sujeitá-los a renovar os saberes e consequentemente suas condutas. E esses aperfeiçoamentos atingem a comunidade, pois, a partir desse olhar crítico para a realidade vivenciada, é possível analisar e melhorar a assistência ofertada.

No processo de Educação Permanente, as pessoas atuam como atores reflexivos da prática e construtores do conhecimento e de alternativas de ação, ao invés de receptores ${ }^{1}$. 


\section{Apontando resolução para os problemas e transformando as práticas cotidianas}

O método utilizado nas oficinas de Educação Permanente em Saúde da unidade é visto pelos profissionais que participam do processo como meio de resolutividade para problemas no território. Na fala a seguir, a enfermeira reconhece a potencialidade do Arco de Charles Maguerez e a importância de seguir suas etapas para obter resultados.

"A Teoria do Arco de Charles Maguerez é uma ferramenta rica, pois observa a realidade, definindo problemas e propondo soluções para alcançar os resultados." (Enfermeira 1)

"[...] e no final tem as soluções." (Nutricionista)

No esquema apresentado por Bordenave e Pereira constam cinco etapas que se desenvolvem a partir da realidade ou um recorte da realidade: Observação da Realidade; Pontos-chave; Teorização; Hipóteses de Solução e Aplicação à Realidade ${ }^{4}$.

O seguimento das fases é relevante para os sujeitos do estudo, pois através dele pode-se visualizar possíveis soluções, ou seja, caminhos de intervenção para aqueles problemas levantados. As propostas resultantes desta etapa têm expressivo valor, pois consideram a realidade dos profissionais, suas opiniões e saberes e estão em harmonia com a equipe.

Nesta metodologia, as hipóteses são construídas após o estudo, como fruto da compreensão profunda que se obteve sobre o problema, investigando-o de todos os ângulos possíveis $^{12}$.

Foram apontadas contribuições da utilização do método do arco de Charles Maguerez capazes de proporcionar mudanças nas condutas dos profissionais assim como na organização do serviço. Trata-se não só de modificações no fazer de cada um da equipe e sua organização, mas também de mudanças práticas no território.

\footnotetext{
"Tinham algumas coisas que a gente percebia que fazia, mas tinha outras que não estava fazendo." (Enfermeira 3)

"Toda vez quando eu vou pensar em Educação Permanente já lembro o que tenho que fazer, como tenho que fazer devido ao método." (Gerente)
}

Os processos de Educação Permanente em Saúde têm como objetivos a transformação das práticas profissionais e da própria organização do trabalho ${ }^{1}$. A seguinte fala da gerente da unidade remete a várias mudanças práticas que passaram a acontecer a partir do desenvolvimento de oficinas com base na teoria do Arco de Charles Maguerez. Trata-se de práticas relacionadas a diferentes temas trabalhados nas oficinas e que partiram de pactuações e levantamentos de soluções, como proposto na quarta fase.

\begin{abstract}
"Tentamos montar uma equipe de urgência e emergência, a questão da organização dos grupos em especial o grupo de gestantes. [...] fizemos um livro de registro só para tuberculose, e um formulário para acompanhar melhor esses pacientes. A gente pactuou que a testagem rápida de gestantes seria na primeira consulta. Não estava sendo porque nem todas as enfermeiras eram capacitadas, mas, mesmo assim, elas viram a necessidade de realizar na primeira consulta de pré-natal. Os próprios enfermeiros e pessoal de nível superior sentiu necessidade de fazer um grupo de estudos. O arco estimulou o estudo e a querer buscar conhecimento." (Gerente)
\end{abstract}

Nesta metodologia, as hipóteses são construídas após o estudo, como fruto da compreensão profunda que se obteve sobre o problema, investigando-o de todos os ângulos possíveis $^{12}$.

A profissional de enfermagem, em sua fala, retrata a implantação de kits de urgência e emergência, incluindo um específico para casos obstétricos. É um resultado de uma oficina cujo tema foi eleito devido à ocorrência de partos domiciliares no território, segundo conversa informal com os entrevistados.

"Foram feitos kits de urgência e emergência, foram feitos kits parto. Se acontecer alguma coisa, existe na unidade." (Técnica de Enfermagem 1).

Outra mudança citada se refere à troca de saberes e práticas entre os próprios profissionais, o que propicia a interação entre diferentes categorias e promove uma formação mais holística e uma visão integral do cuidado. A lógica da Educação Permanente é descentralizada, ascendente, multiprofissional e transdisciplinar. Envolve mudanças nas relações, nos processos, nos produtos e, principalmente, nas pessoas ${ }^{15}$.

"Torna 'multi' porque você acaba aprendendo funções que não são suas, mas que vai lhe agregar de alguma forma." (Fonoaudióloga)

"Quando chega a parte da mudança da organização por conta do que foi planejado, eu não vejo fazer." (Enfermeira 4)

Embora seja visível a presença de transformações nas práticas a partir da utilização de oficinas baseadas na teoria do Arco no desenvolvimento de Educação Permanente na unidade de saúde, as falas a seguir retratam a não visualização de mudanças relacionadas à organização do serviço. 
Apesar da não visualização de transformações por alguns profissionais, considera-se completa a execução do Arco, pois foi possível apontar mudanças nas condutas e na rotina do serviço a partir das propostas feitas na etapa de hipóteses de solução. Nesta metodologia pelo menos uma ação deve ser realizada dentro da aplicabilidade proposta, buscando a transformação da realidade existente ${ }^{12}$.

\section{Desafios do uso do método nos momentos de Educação Permanente em Saúde na Estratégia Saúde Família}

O desconhecimento do método utilizado nas oficinas é considerado um limite na aplicação, pois demonstra que alguns profissionais inseridos no processo às vezes atuavam como facilitadores e não tinham o conhecimento sobre a denominação. O que, muitas vezes, torna-se um empecilho para que haja um seguimento das fases propostas e consequentemente dos resultados que se pode obter.

\begin{abstract}
"A limitação é porque nem todo mundo conhece, como eu que estava usando e não sabia nem o que era que eu estava usando. Então assim, você acaba fazendo aquilo ali por uma prática que você teve em alguma outra reunião, mas você não vai a fundo porque não conhece o método." (Nutricionista)

"Eu acho que não sei muito aprofundado como que é." (Enfermeira 4)
\end{abstract}

No discurso da gerente da unidade constatamos que os profissionais passaram por capacitações e esclarecimentos sobre a teoria, porém no momento em que precisam aplicar, não possuem aptidão para fazê-lo. Surgem então questionamentos sobre a forma como esses conhecimentos foram repassados e qual nível de aprofundamento foi alcançado nestes treinamentos, já que aparentemente não foi absorvida grande parte do assunto.

"E os limites são que nem todos os profissionais conseguem aplicar porque não conhecem e não buscam conhecer. [...] Apesar de a gente já ter feito algumas capacitações com os residentes, com alguns profissionais. [...] acho que por falta de prática de seguir o arco." (Gerente)

É importante que, ao adotar o papel de facilitador, o profissional de saúde esteja inteirado do processo e do método utilizado. É deles que parte a condução dos participantes a fim de seguir as fases do Arco, objetivando e alcançando o intuito de cada uma delas.

Foram obtidas também sugestões feitas pelos mesmos para aperfeiçoar o processo de Educação Permanente no qual estão inseridos. Surgiram propostas relacionadas à periodicidade desses momentos e a busca de conhecer mais sobre o método utilizado.

Também indicaram formas de tornar as atividades de Educação Permanente mais produtivas como reservar um momento apenas para essa finalidade. Alguns julgam que é preciso ir além do encontro mensal e aumentar a frequência dos momentos de EPS.

"Melhor mesmo seria em outro dia que não fosse da roda." (ACS 1)

"Mais educação permanente nas rodas, porque é muito pouco uma vez por mês." (Técnica de Enfermagem 3)

Outra demanda apontada pelos entrevistados foi a necessidade de aprofundar os conhecimentos sobre o Arco de Charles Maguerez. Principalmente visando facilitar a compreensão dos facilitadores e a melhor condução dos momentos de Educação Permanente. Acredita-se que a aquisição desses conhecimentos tem capacidade de potencializar o processo, pois, a partir da transformação das práticas pelo uso da teoria do Arco, é possível que a equipe se habitue em executar melhor as fases e obtenha melhores resultados.

"Relembrar o método, principalmente para os profissionais que estão sempre à frente." (Enfermeira 2)

"Relembrar sempre para que os profissionais percebam como que vai se trabalhar e depois de um tempo seja um processo natural." (Enfermeira 4)

No seguinte discurso, a gerente do CSF aborda a necessidade de articular momentos para estudar a teoria do Arco de Charles Maguerez junto aos profissionais que compõem a equipe. Propõe, inclusive, a elaboração de uma tecnologia para ajudar na compreensão e servir de consulta para os facilitadores das rodas de Educação Permanente.

\begin{abstract}
"Como há uma mudança muito grande de profissionais teria que articular uma capacitação para os profissionais constantemente. Porque eu acho que eles esquecem como seria a teoria. Então teria que estabelecer algum fluxo para relembrar. Não sei, um manual para quem for planejar a roda. Porque assim, toda quinta-feira tem uma equipe que cuida da roda, então aquela equipe que fosse planejar a roda de EP tivesse um manual de como aplicar o arco, como executar todas as etapas do arco no processo de Educação Permanente." (Gerente)
\end{abstract}

O conhecimento sobre o método utilizado nos momentos de Educação permanente é uma necessidade percebida pelos próprios profissionais e requer atenção, pois através da apropriação do método é possível tornar as oficinas mais sistemáticas como referido anteriormente, e capazes de 
promover mudanças positivas para o serviço, uma vez que o seguimento das etapas conduz o processo da realidade do qual parte para a realidade na qual se busca fazer mudanças.

\section{CONSIDERAÇÕES FINAIS}

O uso do método de oficinas com base na teoria do Arco de Charles Maguerez é significativo e possibilita aos profissionais que participam do processo de Educação Permanente repensar e reconstruir suas próprias práticas por meio da identificação de problemas no território e da organização de soluções convenientes. Foi possível identificar a visão dos sujeitos do estudo sobre o processo em que estão inseridos de forma significativa em relação às potencialidades da teoria do Arco de Maguerez, suas contribuições e também às dificuldades na aplicação.

É necessário planejar formas de abordar a teoria e de uma forma homogênea, tornar o método do Arco mais presente no cotidiano dos profissionais de saúde. Pois, sendo uma demanda sinalizada pelos próprios entrevistados, merece a atenção dos gestores. É preciso articulação para estudar a teoria utilizada nos momentos de Educação Permanente em Saúde junto à equipe ou mesmo considerar a elaboração de tecnologias para ajudar na compreensão e servir de consulta para os participantes e facilitadores das oficinas.

Acredita-se que dados obtidos a partir deste estudo possam contribuir com as atividades de Educação Permanente desenvolvidas na Estratégia Saúde da Família, pois foi possível identificar limitações e levantar propostas dos profissionais enquanto equipe participante do processo.

O uso da teoria do Arco de Charles Maguerez provocou envolvimento com a realidade vivenciada, com as potencialidades do território e da própria equipe. Esses resultados podem servir de retorno tanto para o serviço quanto para a Estratégia Saúde da Família de modo que desperte reflexões sobre o processo de Educação Permanente em Saúde e a forma como tem sido realizado.

\section{REFERÊNCIAS}

1. Brasil. Ministério da Saúde. Secretaria de Gestão do Trabalho e da Educação na Saúde. Departamento de Gestão da Educação em Saúde. Política Nacional de Educação Permanente em Saúde. Brasília: Ministério da Saúde; 2009.
2. Peduzzi M, Guerra DAD, Braga CP, Lucena FS, Silva JAM. Atividades educativas de trabalhadores na atenção primária: concepções de educação permanente e de educação continuada em saúde presentes no cotidiano de unidades básicas de saúde em São Paulo. Interface (Botucatu). 2009;13(30):121-34. https://doi.org/10.1590/ S1414-32832009000300011

3. Berbel NAN. A metodologia da problematização no ensino superior e sua contribuição para o plano da práxis. Semina Ciênc Soc Hum. 1996;17(esp):7-17.

4. Bordenave JD, Pereira AM. Estratégias de ensino-aprendizagem. 25a ed. Rio de Janeiro: Vozes; 2004.

5. Minayo MCS. O desafio do conhecimento: pesquisa qualitativa em saúde. 12ª ed. São Paulo: Hucitec; 2010.

6. Berbel NAN. A pesquisa em didática e prática de ensino através da metodologia da problematização. In: Anais do XII Encontro Nacional de Didática e Práticas de Ensino. Curitiba/PR: ENDIPE; 2004.

7. Lefevre F, Lefevre AMC, Teixeira JJV. O discurso do sujeito coletivo: uma nova abordagem metodológica em pesquisa qualitativa. Caxias do Sul: Edus; 2005.

8. Brasil. Lei no 11.350 , de 5 de outubro de 2006. Dispóe sobre o aproveitamento de pessoal amparado pelo parágrafo único do art. 2을 Emenda Constitucional no 51, de 14 de fevereiro de 2006, e dá outras providências. DOU. 2006 out. 5.

9. Souza FL, Ponte MAC, Linhares AKN, Cavalcante AN, Dias MSA, Soares C, Tajra FS, Teixeira EH. A Política municipal de educação permanente em Sobral-CE. Sanare. 2008;7(2):14-22.

10. Berbel NAN. Metodologia da problematização: fundamentos e aplicações. Londrina: INP/UEL; 1999.

11. Bordenave JED. O que é participação. São Paulo: Brasiliense; 1994.

12. Berbel NAN. A problematização e a aprendizagem baseada em problemas: diferentes termos ou diferentes caminhos? Interface (Botucatu). 1998;2(2):139-54. https://doi.org/10.1590/S141432831998000100008

13. Mitre SM, Batista RS, Mendonça JMG, Pinto NMM, Meirelles CAB, Porto CP, Moreira T, Hoffmann LMA. Metodologias ativas de ensinoaprendizagem na formação profissional em saúde: debates atuais. Cien Saude Colet. 2008;1(2):2133-44. https://doi.org/10.1590/ S1413-81232008000900018

14. Prado ML, Velho MB, Espíndola DS, Sobrinho SH, Backes VMS. Arco de Charles Maguerez: refletindo estratégias de metodologia ativa na formação de profissionais de saúde. Esc Anna Nery. 2012;16(1):1727. https://doi.org/10.1590/S1414-81452012000100023

15. Mancia JR, Cabral LC, Koerich MS. Educação permanente no contexto da enfermagem e na saúde. Rev Bras Enferm. 2004;57(5):605-10. https://doi.org/10.1590/S0034-71672004000500018 